\title{
Predictors of moral distress among nurses working in Jimma University Medical Center, South West Ethiopia
}

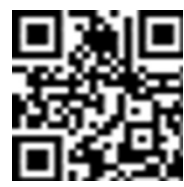

Original article

Habtam Abebaw Beyaffers, Marta Tessema Woldetsadik, Admasu Belay Gizaw*

School of Nursing and Midwifery, Jimma University Institute of Health, Jimma Oromia 378, Ethiopia

Received: 1 May 2020; Accepted: 11 June 2020; Published: 20 December 2020

\begin{abstract}
Background: Moral distress is characterized by biopsychosocial, cognitive, and behavioral effects experienced by clinicians when their values are compromised by internal or external constraints, which results in the inability to give the desired care to patients. Objective: To assess predictors of moral distress among nurses working in Jimma University Medical Center, South West Ethiopia. Methods: An institution-based cross-sectional study design was used. A simple random sampling technique was applied to select a total of 248 study participants. Data were collected using a structured self-administered questionnaire, which contains sociodemographic characteristics, Moral Distress Scale-Revised, personal factors, and organizational factors. The data were entered into Epi-data version 3.1 and analyzed by SPSS software version 20. Descriptive statistics, bivariate analysis, and multivariable logistic regression analysis were performed. Finally, $P$-value $<0.05$ was used to declare and include variables with statistically significant in predicting the outcome variable.

Results: More than two-thirds of the study participants 170 (68.5\%) were females. The mean age of the respondents is 29 years. Among the study participants, 174 (70.16\%) nurses had experienced a high level of moral distress. Sex, working hours, professional commitment, autonomy, and working environment were statistically significant predictors of moral distress.

Conclusions: More than two-thirds of the nurses were experiencing a high level of moral distress. This will affect the nursing service quality, nurses, the nursing profession, and the organization as a whole. This finding is critical for the study since the problem is happening in the presence of low nurse to patient ratio and low nursing care quality. Sex, working hours per week, professional commitment, autonomy, and working environment were identified as predictors of moral distress.
\end{abstract}

Keywords: moral distress $\bullet$ nurses $•$ JUMC $・$ Ethiopia

(c) Shanxi Medical Periodical Press.

\section{Introduction}

Moral distress is defined as the biopsychosocial, cognitive, and behavioral effects experienced by clinicians when their values are compromised by internal or external constraints; it results from the inability to provide the desired care to patients. ${ }^{1}$ It is a pervasive problem in the nursing profession. An inability to act in alignment with one's moral values is detrimental not only to the nurse's well-being but also to patient care and clinical practice as a whole. ${ }^{2}$

Moral distress among nurses causes decreased job satisfaction, turnover, burnout, and psychological distress. Nurses are the ones who are affected by moral distress compared to other health care

How to cite this article: Beyaffers HA, Woldetsadik MT, Gizaw AB. Predictors of moral distress among nurses working in Jimma University Medical Center, South West Ethiopia. Front Nurs. 2020;4:369-378. 
providers due to long interactions and relationships with patients. ${ }^{3}$ This problem exists because of clinical conditions, environmental sites, and external and internal factors. ${ }^{4-6}$

Moral distress happens when the internalenvironment of nurses' ideas, faith, individual personality, duty, communication challenges, and supposed obligations is mismatched with the requirements of the outside work environment. ${ }^{7,8}$

Because of moral distress, nurses experience physical and psychological problems and manifests most often with symptoms, such as frustration, anger, anxiety, guilt, loss of self-worth, depression, nightmares, and physical reactions, such as sweating, shaking, headaches, and crying. ${ }^{9}$ Healthcare providers who are frequently exposed to these situations feels as if they cannot carry out what they consider to be ethically right actions. Rather they are potentially focused on moral distress, which leads to job dissatisfaction, burnout, and leaving a job or even the profession. ${ }^{10}$

Studies in clinical settings have associated moral distress with low self-confidence and increased turnover. An estimated 880,000 nurses in the United States or one in three nurses experience moral distress. ${ }^{11-13}$ Moral distress has continuous effects on the nurse's satisfaction, retention, and recruitment and has negative implications of patient care. ${ }^{14}$ This problem may affect nurses on their job environment or quality of nursing care, thus an examination of moral distress is a significant issue..$^{15,16}$ Moral distress in the hospital environment affects nurses resulting in feelings, such as depression, emotional disequilibrium, affect patients, and exit from nursing profession. ${ }^{17,18}$

Emotional manifestations of moral distress, which has been seen as a psychological imbalance that nurses experience when facing barriers, impeded to perform interventions. The feeling of powerlessness can be increased with the development of guilty feelings among nursing professionals. ${ }^{19}$ Thus, further investigation of how various factors contribute to moral distress is very important. Therefore, this study aimed to determine the predictors of moral distress and describe the relationship of variables among the study subjects.

\section{Methods and materials}

\subsection{Study area and period}

The study was conducted in Jimma University Medical Center (JUMC), Jimma Town, Jimma Zone, South West Ethiopia. Geographically, the study center is located in Jimma city $352 \mathrm{~km}$ southwest of the capital city of Ethiopia, Addis Ababa. JUMC is the only teaching and referral hospital in this area providing services for approximately 15,000 inpatients, 160,000 outpatient attendants, 11,000 emergency cases, and 4,500 deliveries in a year. Currently, the hospital has more than 20 specialists of different categories, 27 GP doctors, 541 nurses (185 of them are diploma holders, 343 of them are bachelor degree (BSc) holders, and 13 of them are master degree (MSc) holders), 52 midwifery professionals, 17 anesthetist professionals, 68 pharmacists, and 54 laboratory technicians. All these professionals were included under the hospital administration. However, there are a lot of other professionals, but they were included under the academic administration of Jimma University. The study was conducted from April 9 to May 9, 2019.

\subsection{Study design}

The Institution-based cross-sectional study design was used in this study.

\subsection{Sample size determination}

A total of 248 study participants were taken, and the sample size was determined using a standard of sample size calculation formula for a single population.

\subsection{Sampling procedure and technique}

A list of nurses working in JUMC was obtained from the human resource office of JUMC to obtain the study population. Out of 541 nurses, 248 nurses were calculated as a sample size by proportional allocation in each ward. A simple random sampling technique was applied. The first unit was selected by using the lottery method of sampling.

\subsection{Data collection tools}

Data were collected by using structured selfadministered questionnaires adapted from different sources. The questions were grouped into sociodemographic characteristics, Hamric's Moral Distress Scale-Revised (MDS-R), personal factors, and organizational factors. The socio-demographic characteristics contained nine items. MDS-R instrument was adapted from an instrument developed ${ }^{20}$ by Hamric (1967), which contained nine items, Cronbach's alpha (0.74). ${ }^{14,21}$ Personal factors (professional commitment scale instruments) were adapted from Blau (2003), which contained six items, Cronbach's alpha (0.81). Organizational commitments scale was adapted from the instrument developed by Meyer and Allen (1988, 1990), which contained five items, Cronbach's alpha 
(0.78). The empowerment scale was adapted from the instrument developed by Spreitzer $(1995,1996)$, which contained five items, Cronbach's alpha (0.80). Autonomy in practice scale was adapted from the instrument developed by Dempster, Dempster Practice Behaviors Scale (1990), which contained four items, Cronbach's alpha (0.92). Job satisfaction scale instrument was adapted from Minnesota Satisfaction Questionnaires from Portuguese Hospital Workers, which contained seven items, Cronbach's alpha $(0.85)(71,73) .{ }^{20,22-32}$ The entire above personal factor variables contained a total of 27 items, which were measured by a 4-point Likert scale. Organizational factors (Nursing working environment scale instrument) were adapted from the Practice Environment Scale of Nursing Work Index for nurses, which contained 16 items, Cronbach's alpha (0.89). Perceived organizational support scales were adapted from an instrument developed by Eisenberger et al. (1986), which contained five items, Cronbach's alpha (0.79). Perception toward the quality of nursing care scale was adapted from an instrument developed by Ledoux (2015), which contained one item, Cronbach's alpha (0.72). ${ }^{33,34}$ All of the above organizational factors' variables contained a total of 22 items and were measured by the 4-point Likert scale.

\subsection{Data collection personnel}

Four BSc nurses were data collectors and two MSc nurses were supervisors for the data collection process. Two data collectors came from Agaro hospital, one from Shebe Health Center, and the remaining one from Limu Genet Hospital. The supervisors came from Mizan Tepi University. These persons were recruited based on their experience in data collection.

\subsection{Data collection method and procedures}

Data were collected using a structured self-administered questionnaire. The data were collected in three shifts, that is, in the morning, afternoon, and night. Each selected nurse received an explanation about the purpose of the study. The supervisors supervised the data collectors daily. Finally, the principal investigator collected and compiled the collected data each day.

\subsection{Data quality control}

The principal investigator has given training to the data collectors and the supervisors for 2 days to ensure the quality of the data before the time of data collection. The supervisors and the principal investigator closely followed and monitored data collection procedures. The pre-test was done using $5 \%$ of the total sample size (12 participants) at Shenen Gibe General Hospital. The quality of the collected data was checked for its completeness, clarity, and coherence each day by the supervisors and the principal investigator.

\subsection{Data processing and analysis}

The collected data were entered into Epi-data Version 3.1 , and then it was exported into SPSS Version 20. Descriptive statistics, bivariate analysis, and multivariable logistic regression analysis were used to describe, identify candidate variables, and determine predictor variables, respectively. Finally, the adjusted odds ratio at $95 \% \mathrm{Cl}$ with $P$-value $<0.05$ was considered a statistical significance.

\section{Results}

\subsection{Socio-demographic characteristics}

Among the 248 study population to whom questionnaires were distributed, all respondents returned their questionnaires that make a $100 \%$ response rate. The majority of the participants were young adults (85.1\%). The mean age of the respondents was $29 \pm 5.85$ years. Among the study participants, $68.5 \%$ of them were females and more than half of them were married. Half of the participants were orthodox (50.8\%). Out of the total study participants, $175(70.6 \%)$ of them were degree holders in the nursing profession. Among the 248 participants, $50.4 \%$ of them were $2-4$ years of professional experience in the current units. More than half of the participants $(73.0 \%)$ worked for $42 \mathrm{~h} /$ week. In addition, $66.53 \%$ of the participants earned a monthly income in the range of $2,628-5,000$ birrs (Table 1).

\subsection{Level of moral distress}

Percentage mean score of the level of moral distress $=$ Actual mean score $\div$ Maximum potential score $\times 100=(21.89+36) \times 100=60.8$.

Out of 248 participants, $70.16 \%$ of the participants had a high level of moral distress and only about onethird of the study participants developed a low level of moral distress (Figure 1).

Out of 248 participants, $50 \%$ of the nurses were not committed to their profession and their organization. Concerning professional autonomy more than half of the study participants $(54.8 \%)$ were not autonomous. On the other hand, $138(55.6 \%)$ nurses were not empowered and more than half of them $(52.42 \%)$ did not have job satisfaction. 


\begin{tabular}{|c|c|c|}
\hline Variables & $F$ & $\%$ \\
\hline \multicolumn{3}{|l|}{ Age, years } \\
\hline Young adult (18-35) & 211 & 85.1 \\
\hline Adult (36-45) & 31 & 12.5 \\
\hline Middle age (45-60) & 6 & 2.4 \\
\hline \multicolumn{3}{|l|}{ Sex } \\
\hline Male & 78 & 31.5 \\
\hline Female & 170 & 68.5 \\
\hline \multicolumn{3}{|l|}{ Religion } \\
\hline Orthodox & 126 & 50.8 \\
\hline Muslim & 79 & 31.9 \\
\hline Protestant & 40 & 16.1 \\
\hline Others & 3 & 1.2 \\
\hline \multicolumn{3}{|l|}{ Marital status } \\
\hline Single & 100 & 40.3 \\
\hline Married & 138 & 55.7 \\
\hline Divorced & 6 & 2.4 \\
\hline Windowed & 4 & 1.6 \\
\hline \multicolumn{3}{|l|}{ Level of education } \\
\hline Diploma & 61 & 24.6 \\
\hline Degree & 175 & 70.6 \\
\hline MSc and above & 12 & 4.8 \\
\hline \multicolumn{3}{|c|}{ Working experience, years } \\
\hline $0-2$ & 76 & 30.6 \\
\hline $2-4$ & 125 & 50.4 \\
\hline $4-6$ & 47 & 19.0 \\
\hline \multicolumn{3}{|l|}{ Working hours per week } \\
\hline 42 h/week & 181 & 73.0 \\
\hline 84 h/week & 67 & 27.0 \\
\hline \multicolumn{3}{|l|}{ Monthly income, birrs } \\
\hline $2,628-5,000$ & 165 & 66.5 \\
\hline $5,001-9,028$ & 83 & 33.5 \\
\hline
\end{tabular}

Table 1. Socio-demographic characteristics of the study participants in the study of predictors of moral distress among nurses working at JUMC, South West Ethiopia, April $2019(n=248)$.

\subsection{Bivariate analysis}

Socio-demographic variables on bivariate analysis with a $P$-value of $<0.25$ (sex, level of education, working hours per week, and monthly income) were selected as candidate variables for the final multivariable logistic regression analysis (Table 2 ).

\subsection{Multivariable logistic regression analysis}

According to this study, male nurses were 2.4 times (AOR: 2.42, 95\% Cl: 1.13-5.18) more likely to develop moral distress than females. The nurses who were worked for $42 \mathrm{~h} /$ week were almost 2 times (AOR: 1.96, 95\% Cl: $1.85-2.93)$ more likely to develop a high level of moral distress than nurses who were worked for $84 \mathrm{~h} /$ week. The nurses who were not committed to their profession were 2 times (AOR: $2.01,95 \% \mathrm{Cl}$ : 1.08-1.92) more likely to develop a high level of moral distress than nurses who were committed to their profession. The nurses who were not autonomous were 3 times (AOR: $3.20,95 \% \mathrm{Cl}: 1.89-2.64)$ more likely to develop a high level of moral distress than autonomous nurses. The nurses who were worked in a negative working environment were 2 times (AOR: $1.98,95 \% \mathrm{Cl}$ : 1.05-3.72) more likely to develop a high level of moral distress than nurses who were worked in a positive working environment (Table 3).

\section{Discussion}

The finding of this study revealed that about threefourths $(70.16 \%)$ of the study participants had a high level of moral distress. This finding clearly indicated that more than two-thirds of nursing care provided by nurses in the hospital was compromised due to decreased moral values among nursing professionals. On the other hand, the problem is very serious and needs further intervention when it was related with nurse-to-patient ratio and nurse-to-population ratio in developing countries such as Ethiopia because in subSaharan Africa healthcare professionals to population ratio is low, more specifically nurse-to-patient ratio is much lower. ${ }^{31}$ The finding of this study showed variation compared with the study done in the United States. ${ }^{8}$ This discrepancy might be due to differences of factors that can predispose nurses to moral distress and also might be due to differences in feelings of unmet moral values among nurses in the United States and Ethiopia.

The finding of this study showed that sex was identified as a predictor of moral distress. Male nurses experienced a high level of moral distress compared with female nurses. The finding might be related to poor public value and low self-esteem among male nurses in developing countries. ${ }^{33}$

In other words, this study indicated that working hours per week were also a significant predictor of moral distress. This finding was consistent with the study done in Iran, the United States, and the Netherlands. ${ }^{25,35}$ The similarity might be related to the effect of work overload that may predispose nurses to moral distress irrespective of geographical, economic, and developmental differences. According to this study, nurses who were not committed to their profession experienced moral distress than the committed ones. This finding was similar to the study done in the United States. ${ }^{27,31}$ This might be due to professional commitment where a positive relationship with the moral behavior of the nurses by virtue of professional characteristics and 


\section{Level of Moral Distress among the study Participants}

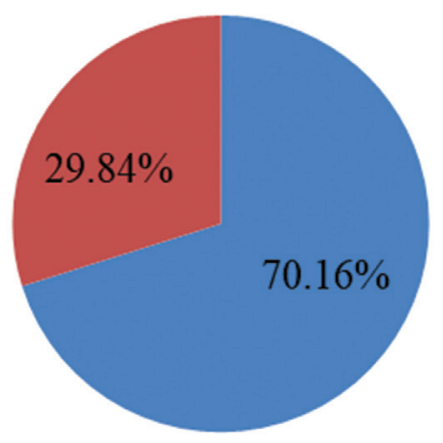

- High Level

Low Level

Figure 1. Level of moral distress among nurses working at Jimma University Medical Center, Jimma Zone, Jimma Town, South West Ethiopia April $2019(n=248)$.

\begin{tabular}{|c|c|c|c|c|}
\hline \multirow[t]{2}{*}{ Variables } & \multicolumn{2}{|c|}{ Level of moral distress } & \multirow[t]{2}{*}{ COR $(95 \% \mathrm{Cl})$} & \multirow[t]{2}{*}{$P$-value } \\
\hline & $\operatorname{High}(N, \%)$ & Low $(N, \%)$ & & \\
\hline \multicolumn{5}{|l|}{ Age } \\
\hline Young adult & 156 (73.9) & $55(26.1)$ & $1.42(0.25-7.96)$ & 0.691 \\
\hline Adult & $14(45.2)$ & $17(54.8)$ & $0.41(0.07-2.59)$ & 0.344 \\
\hline Middle age & $4(66.7)$ & $2(33.3)$ & 1 & \\
\hline \multicolumn{5}{|l|}{ Sex } \\
\hline Male & $63(80.8)$ & $15(19.2)$ & $2.23(1.17-4.26)$ & 0.015 \\
\hline Female & $111(65.3)$ & $59(34.7)$ & 1 & \\
\hline \multicolumn{5}{|l|}{ Religion } \\
\hline Orthodox & $69(54.8)$ & 57 (45.2) & $0.00(0.00)$ & 0.999 \\
\hline Muslim & $68(86.1)$ & $11(13.9)$ & $0.00(0.00)$ & 0.999 \\
\hline Protestant & $34(85.0)$ & $6(15.0)$ & $0.00(0.00)$ & 0.999 \\
\hline Others & $3(100.0)$ & $0(0.0)$ & 1 & \\
\hline \multicolumn{5}{|l|}{ Marital status } \\
\hline Single & $70(70.0)$ & $30(30.0)$ & $1.00(0.24-4.13)$ & 1 \\
\hline Married & $97(70.3)$ & $41(29.7)$ & $1.01(0.25-4.12)$ & 0.985 \\
\hline Divorced & $4(66.7)$ & $2(33.3)$ & $1.03(0.58-6.75)$ & 0.879 \\
\hline Windowed & $3(75)$ & $1(25)$ & 1 & \\
\hline \multicolumn{5}{|l|}{ Level of education } \\
\hline Diploma & $45(73.8)$ & $16(26.2)$ & $14.10(2.80-71.20)$ & 0.001 \\
\hline Degree & $127(72.6)$ & $48(27.4)$ & $13.20(2.80-62.60)$ & 0.001 \\
\hline MSc and above & $2(16.7)$ & $10(83.3)$ & 1 & \\
\hline \multicolumn{5}{|c|}{ Working experience, years } \\
\hline $0-2$ & $29(38.2)$ & $47(61.9)$ & $0.45(0.07-2.66)$ & 0.375 \\
\hline $2-4$ & $68(54.4)$ & $57(45.6)$ & $0.88(0.41-1.89)$ & 0.453 \\
\hline $4-6$ & $27(57.5)$ & $20(42.6)$ & 1 & \\
\hline \multicolumn{5}{|c|}{ Working hours per week } \\
\hline $42 \mathrm{~h} /$ week & $97(53.6)$ & $84(45.4)$ & $2.36(1.35-4.18)$ & 0.063 \\
\hline $84 \mathrm{~h} /$ week & $22(32.8)$ & $45(67.2)$ & 1 & \\
\hline
\end{tabular}




\begin{tabular}{|c|c|c|c|c|}
\hline \multirow[t]{2}{*}{ Variables } & \multicolumn{2}{|c|}{ Level of moral distress } & \multirow[t]{2}{*}{ COR $(95 \% \mathrm{Cl})$} & \multirow[t]{2}{*}{$P$-value } \\
\hline & $\operatorname{High}(N, \%)$ & $\operatorname{Low}(N, \%)$ & & \\
\hline \multicolumn{5}{|l|}{ Monthly income, birrs } \\
\hline $2,628-5,000$ & $123(74.5)$ & $42(25.5)$ & $1.84(1.02-3.13)$ & 0.042 \\
\hline $5,001-9,028$ & $51(61.5)$ & $32(38.5)$ & 1 & \\
\hline \multicolumn{5}{|c|}{ Professional commitment } \\
\hline Not committed & $93(75)$ & $31(25)$ & $1.59(0.92-2.73)$ & 0.077 \\
\hline Committed & $81(65.3)$ & $43(34.7)$ & 1 & \\
\hline \multicolumn{5}{|c|}{ Organizational commitment } \\
\hline Not committed & $88(70.4)$ & 37 (29.6) & $1.10(0.66-1.97)$ & 0.637 \\
\hline Committed & $84(68.3)$ & $39(31.7)$ & 1 & \\
\hline \multicolumn{5}{|l|}{ Autonomy } \\
\hline Not autonomous & $81(59.6)$ & $55(40.5)$ & $2.75(1.74-4.57)$ & 0.068 \\
\hline Autonomous & 39 (34.8) & $73(65.2)$ & 1 & \\
\hline \multicolumn{5}{|l|}{ Empowerment } \\
\hline Not empowered & $103(74.6)$ & $35(25.4)$ & $1.6(0.94-2.79)$ & 0.086 \\
\hline Empowered & $71(64.5)$ & 39 (35.5) & 1 & \\
\hline \multicolumn{5}{|l|}{ Job satisfaction } \\
\hline Not satisfied & $97(74.6)$ & $33(25.4)$ & $1.57(0.91-2.71)$ & 0.109 \\
\hline Satisfied & $77(65.3)$ & $41(34.7)$ & 1 & \\
\hline \multicolumn{5}{|l|}{ Working environments } \\
\hline Not conducive & $96(74.4)$ & $33(25.6)$ & $1.5(0.89-2.64)$ & 0.128 \\
\hline Conducive & $78(65.5)$ & $41(34.5)$ & 1 & \\
\hline \multicolumn{5}{|c|}{ Perception toward the quality of nursing care } \\
\hline Poor perception & $100(72.5)$ & $38(27.5)$ & $1.28(0.74-2.21)$ & 0.375 \\
\hline Good perception & $74(67.3)$ & $36(32.7)$ & 1 & \\
\hline \multicolumn{5}{|c|}{ Perception of organizational support } \\
\hline Poor perception & $92(70.2)$ & $39(29.8)$ & $1.01(0.60-1.74)$ & 0.980 \\
\hline Good perception & $82(70.1)$ & $35(29.9)$ & 1 & \\
\hline
\end{tabular}

Note: The Odds ratio at $95 \% \mathrm{Cl}$ with $P$-value $<0.25$ was a candidate for the final regression model.

Table 2. Bivariate analysis of socio-demographic variables among nurses working at Jimma University Medical Center, Jimma Zone, Jimma Town, South West Ethiopia, April $2019(n=248)$.

common professional and ethical principles shared by nurses all over the world. The finding from this study showed nurses who were not autonomous experienced a high level of moral distress than autonomous nurses. This finding is in line with the study done in Iran. ${ }^{35,36}$ The similarity might be due to the close relationship between moral value and having the right to self-determination among nurses. Both of these variables are the internal drive that the professionals have internally and want to practice them in the real work life when conditions are favorable.

In this study, the working environment was a significant predictor of moral distress among nurses. Nurses who were working in an unfavorable working environment experienced more moral distress than nurses who were working in a conducive working environment. This study was consistent with the study done in Sweden ${ }^{25}$ and the United States. ${ }^{28,37}$ The similarity might be due to a strong relationship among the working environment, job performance, moral value, and moral distress in a given healthcare organization. A conducive working environment may increase job performance, job satisfaction, and decrease moral distress, and thereby increase nursing care quality.

In this study, job satisfaction was negatively correlated with moral distress. This finding was consistent with the study done in Japan ${ }^{38}$ and the United States. ${ }^{13,39}$ This might be due to the indirect or reverse relationship between the two variables.

\section{Conclusions}

Moral distress is a challenging phenomenon all over the world with different levels of severity, and it is the 


\begin{tabular}{|c|c|c|c|c|c|}
\hline \multirow[t]{2}{*}{ Variables } & \multicolumn{2}{|c|}{ Level of moral distress } & \multirow[t]{2}{*}{ COR } & \multirow[t]{2}{*}{ AOR (95\% Cl) } & \multirow[t]{2}{*}{$P$-value } \\
\hline & High & Low & & & \\
\hline \multicolumn{6}{|l|}{ Sex } \\
\hline Male & 63 & 15 & 2.23 & $2.42(1.13-1.88)$ & 0.023 \\
\hline Female & 111 & 59 & 1 & 1 & \\
\hline \multicolumn{6}{|l|}{ Monthly income, birrs } \\
\hline $2,628-5,000$ & 123 & 42 & 1.84 & $0.52(0.15-1.75)$ & 0.288 \\
\hline $5,001-9,028$ & 51 & 32 & 1 & 1 & \\
\hline \multicolumn{6}{|l|}{ Level of education } \\
\hline Diploma & 45 & 16 & 14.10 & $0.89(0.08-10.29)$ & 0.925 \\
\hline Degree & 127 & 48 & 13.20 & $0.87(0.10-7.22)$ & 0.893 \\
\hline MSc and above & 2 & 10 & 1 & 1 & \\
\hline \multicolumn{6}{|c|}{ Working hours per week } \\
\hline 42 h/week & 97 & 84 & 2.40 & $1.96(1.85-2.93)$ & 0.041 \\
\hline $84 \mathrm{~h} /$ week & 22 & 45 & 1 & 1 & \\
\hline \multicolumn{6}{|l|}{ Job satisfaction } \\
\hline Not satisfied & 97 & 33 & 1.57 & $1.36(0.71-2.62)$ & 0.358 \\
\hline Satisfied & 77 & 41 & 1 & 1 & \\
\hline \multicolumn{6}{|c|}{ Professional commitment } \\
\hline Not committed & 93 & 31 & 1.59 & $2.01(1.08-1.92)$ & 0.029 \\
\hline Committed & 81 & 43 & 1 & 1 & \\
\hline \multicolumn{6}{|l|}{ Autonomy } \\
\hline Not autonomous & 81 & 55 & 2.75 & $3.20(1.89-2.64)$ & 0.015 \\
\hline Autonomous & 39 & 73 & 1 & 1 & \\
\hline \multicolumn{6}{|l|}{ Empowerment } \\
\hline Not empowered & 103 & 35 & 1.62 & $1.74(0.91-3.34)$ & 0.095 \\
\hline Empowered & 71 & 39 & 1 & 1 & \\
\hline \multicolumn{6}{|c|}{ Working environments } \\
\hline Negative & 96 & 33 & 1.53 & $1.98(1.05-3.72)$ & 0.035 \\
\hline Positive & 78 & 41 & 1 & 1 & \\
\hline
\end{tabular}

Note: Adjusted odds ratio at $95 \% \mathrm{Cl}$ with $P$-value $<0.05$ was of statistical significance.

Table 3. Multivariable logistic regression analysis of predictors of moral distress among nurses working at Jimma University Medical Center, Jimma Zone, Jimma Town, South West Ethiopia, April $2019(n=248)$.

current problem and the major challenging issue among nurses. The problem has also similar characteristics in this study area too. The finding revealed that more than two-thirds of the nurses experienced high levels of moral distress. This finding is critical for the study since the problem is happening in the presence of a low nurse-to-patient ratio and a low nursing care quality. Sex, working hours per week, professional commitment, autonomy, and working environment were identified as predictors of moral distress. These factors can be a leading cause of the decreasing nurses' sense of well-being, the increasing nurses turnover, and the negative effects on the quantity and quality of patient cares. Due to the presence of lower nurse-to-patient and nurse-to-population ratios and low nursing care quality, the existing nursing services were compromised due to moral distress among nurses. The results of this study showed that the level of moral distress was high. Therefore, it is necessary to revise working hours, provide a supportive environment in the hospital, and consider different strategies that can help to address issues related to low professional commitment and professional autonomy to decrease moral distress.

\section{Acknowledgments}

The authors would like to thank Jimma University, Jimma University Medical Center, Data collectors, and study participants of this study. 


\section{Ethical approval}

Ethical clearance to conduct this study was assured by Jimma University Ethical Review Board. An approval letter was obtained from Jimma University Institute of Health Faculty of Health Science School of Nursing and Midwifery. Formal letters were given to Shenen Gibe General Hospital and JUMC to conduct the pre-test and also main study, respectively. The objective of the study

\section{References}

1. Rushton $\mathrm{CH}$. CE: moral distress: a catalyst in building moral resilience. Am J Nurse. 2016;116:40-49.

2. Hiler CA, Hickman RL, Jr, Reimer AP, Wilson K. Predictors of moral distress in a US sample of critical care nurses. Am J Crit Care. 2018;27:59-66.

3. The American Nurses Association Professional Issues Panel on Moral Resilience. Call to Action: Exploring Moral Resilience Toward a Culture of Ethical Practice. Silver Spring, MD: ANA; 2017.

4. Hamric AB, Davis WS, Childress MD, Moral distress in a nurse and a physician. J Pharos/ Winter. 2006;3:16-22.

5. Wilson MA, Armitage CN. Barriers and values of moral distress among critical care nurses. J Aerosp Med. 2017;88:1-31.b

6. Baldwin KMP. Moral distress and ethical decision making. J Nurs Cent. 2014;8:5.

7. Ong WY, Yee CM, Lee A. Ethical dilemmas in the care of cancer patients near the end of life. J Med. 2012;53:11.

8. Hassan MA, Asfourand HI, Reda NA. Moral distress related factors affecting critical care nurses. J Am Sci. 2013;9:184-196.

9. Lerkiatbundit S, Borry P. Moral distress part I: critical literature review. Thai J Pharm Pract. 2009;1:640-650.

10. Ameri M, Mirhashemi B, Hosseini SS. Moral distress and the contributing factors among nurses in different work environments. J Nurs Midwifery Sci. 2015;2:44-49.

11. Lerkiatbundit S, Borry P. Moral distress part II: critical review of measurement. J Pharm Pract. 2009;13:17-18.

12. Allen R, Hm MSM, Judkins-Cohn T, et al. Moral distress among healthcare professionals at a health system. J Oncol Nurs. 2013;15:111-118.

13. Redman BK, Fry ST. Nurses' ethical conflicts: what is really known about them? Nurse Ethics. 2000;7:360-366.

14. Musto LC, Rodney PA, Vanderheide R. Barriers and values of moral distress among critical care nurses. was explained to the study participants. Verbal consent was taken before starting the data collection. The confidentiality of the participants was kept throughout the whole study.

\section{Conflicts of interest}

All contributing authors declare no conflicts of interest.

Toward Interventions to address moral distress. Nurs Ethics. 2016;22:91-102.

15. de Veer AJ, Francke AL, Struijs A, Willems DL. Determinants of moral distress in daily nursing practice: a cross sectional correlational questionnaire survey. Int J Nurs Stud. 2013; 50:100-108.

16. Hamric AB, Borchers CT, Epstein EG. Development and testing of an instrument to measure moral distress in healthcare professionals. AJOB Primary Research. 2012; 2: 1-9.

17. Hatamizadeh M, Hosseini M, Bernstein C, Ranjbar $\mathrm{H}$. Health care reform in Iran: implications for nurses' moral distress, patient rights, satisfaction and turnover intention. J Nurs Midwifery Res. 2018;17:1-8.

18. Corrado AM, Molinaro ML. Moral distress in health care professionals. Am Assoc Coll Nurs Ethics. 2017;86:32-34.

19. Stratton E. Moral distress in nursing academia presenting grounded theory: introduction. In: American Association of Colleges of Nursing. Special Survey of Vacant Faculty Positions for Academic Year; 2013, 2014:4-7.

20. Liu L, Hu S, Wang L, Sui G, Ma L. Positive resources for combating depressive symptoms among Chinese male correctional officers: perceived organizational support and psychological capital. BMC Psychiatry. 2013;13:89.

21. Gradner DL. Career commitment in nursing. J Prof Nurs. 1992;8:155-160.

22. Wilkinson JM. Moral distress in nursing practice, experience and effect. J Nurs Forum. 2011;23:13-19.

23. Dalmolin GDL, Luiz E, Barlem D. Implications of moral distress on nurses and burn out. Text Context Nurs. 2012;21:200-208.

24. Baghbani G. The relationship between organizational commitment, job satisfaction and social orientation, and the nurses' moral behavior. Med Ethics J. 2016;10:37.

25. Sherman R, Pross E. Growing future nurse leaders to build and sustain healthy work environments at 
the unit level. Online J Issues Nurs. 2010;15: No. 1, Manuscript 1.

26. Wurzbach ME. Comfort and nurses' moral choices. J Adv Nurs. 1996;24:260-264.

27. Pendry PS. Moral distress: recognizing it to retain nurses. Nurs Econ. 2007;25:217-221.

28. Vaziri MH. Moral distress among Iranian nurses. Iran J Psychiatry. 2015;10:32-36.

29. Korkmaz F, Mustafbaylı Ö, Yerlikaya I. Moral problems experienced by nurses. Ankara Med J. 2018;18:231-309.

30. Lankshear S, Kerr MS, Spence Laschinger HK, Wong CA. The professional practice leader: the role of organizational power and personal influence in creating a professional practice environment for nurses. Health Care Manage Rev. 2013;38: 349-360.

31. Munjanja O, Kibuka S, Dovlo D. The Global Nursing Review Initiative. The Nursing Workforce in SubSaharan Africa. Geneva, Switzerland: International Council of Nurses Report Issue Paper. 2005; 7:17.

32. Kwak C, Chung BY, Xu Y, Eun-Jung C. Relationship of job satisfaction with perceived organizational support and quality of care among South Korean nurses: a questionnaire survey. Int J Nurs Stud. 2010;47:1292.

33. Mohamed S. Relationship among public nursing image, self-image, and self-esteem of nurses. IOSR J Nurs Health Sci (IOSR-JNHS). 2018;7:10-16.

34. Ledoux K. Understanding compassion fatigue: understanding compassion. J Adv Nurs. 2015;1:5-6.

35. Blau GJ. The measurement and prediction of career commitment. J Occup Psychol. 1985;58:277-288.

36. Fu JR. Understanding career commitment of IT professionals: perspectives of push-pull-mooring framework and investment model. Int J Inf Manage. 2010;31:279-293.

37. Abdollahi B, Karimian H, Namdari Pejman M. Relationship between organizational commitment and spirituality in the workplace with ethical behavior of employees. Ethics Sci Technol. 2015;9:1-10.

38. Sarkoohijabalbarezi Z. The relationship between professional autonomy and moral distress among nurses working in children's units and pediatric intensive care wards. Int J Nurs Sci. 2017;4:117-121.

39. Lazzarin M, Biondi A, di Mauro S. Moral distress in nurses in oncology and hematology units. Nurse Ethics. 2012;19:183-195. 